\title{
Improving The Ability of Self-Caring of Leprosy Survivor Through Family Psychoeducation
}

\author{
Muhamad Amang Handaris ${ }^{1}$, Shanti Rosmaharani' ${ }^{1}$, Rodiyah Rodiyah ${ }^{1}$
}

$1 \quad$ STIKES Pemkab Jombang

\begin{tabular}{|c|c|}
\hline Article Info & Abstract \\
\hline $\begin{array}{l}\text { Article History: } \\
\text { Submitted: May 19th }, 2021 \\
\text { Accepted: May } 30^{\text {th }}, 2021 \\
\text { Published: May } 31^{\text {st }}, 2021 \\
\text { Keywords: } \\
\text { Family Psychoeducation; } \\
\text { Self-Care; Leprosy }\end{array}$ & $\begin{array}{l}\text { Leprosy survivor not only suffers physical damage but also suffer } \\
\text { psychosocially because of environmental behaviour that causes problems } \\
\text { and impacts on their families and sufferers. One way that can be used to } \\
\text { overcome this dependence is family psychoeducation. This study aims to } \\
\text { determine the effect of family psychoeducation on self-care in leprosy } \\
\text { survivor in Jombang. The design of this study was a pre-experimental one- } \\
\text { group pre-post test design. The population of the family who had been } \\
\text { infected with leprosy were } 22 \text { people. The sample size was } 22 \text { respondents } \\
\text { using total sampling. Data analysis using the Wilcoxon Signed Ranks Test. } \\
\text { The results showed that before family psychoeducation } 54.5 \% \text { of self-care } \\
\text { was good as many as } 12 \text { families but after psychoeducation, the family was } \\
77.3 \% \text { good as many as } 17 \text { families. The Wilcoxon test shows the } \rho \text {-value } \\
(0.025)<0.05 \text {, which means that there is an effect of family psychoeducation } \\
\text { on self-care in leprosy survivor. Family psychoeducation has a positive } \\
\text { impact on the family, which can improve the ability of the family to carry out } \\
\text { self-care independently at home. It can be concluded that family } \\
\text { psychoeducation is effective for improving self-care in leprosy survivor. This } \\
\text { therapy is expected to be applied so that there is a change in the level of the } \\
\text { family's ability to carry out self-care. }\end{array}$ \\
\hline
\end{tabular}

\section{PENDAHULUAN}

Kusta adalah salah satu jenis penyakit granulomatosa bagian syaraf tepi dan di mukosa pada saluran pernafasan bagian atas, adanya luka di kulit merupakan salah satu tanda kusta yang jika tidak segera di tangani dapat menyebabkan kerusakan progresif pada bagian kulit dan jika di biarkan kusta dapat menyebabkan kerusakan pada bagian kulit, saraf, ekstrimitas dan mata [1]. Kusta sampai saat ini masih ditakuti oleh sebagian besar masyarakat Indonesia karena kurangnya pengetahuan terhadap penyakit tersebut.

Pengetahuan yang kurang akan memberikan dampak negatif yaitu berupa stigma sosial atau penilaian negatif berdasarkan reaksi emosi dan dimaksudkan untuk mengucilkan yang kerap dihubungkan dengan sosial budaya masyarakat terhadap kusta. Penderita/penyintas kusta mengalami masalah ganda, tidak hanya menderita secara fisik saja tetapi juga mengalami

Corresponding author:

Shanti Rosmaharani

shantirosmaharani@gmail.com

Media Keperawatan Indonesia, Vol 4 No 2, May 2021

e-ISSN: 2615-1669

ISSN: 2722-2802

DOI: $10.26714 / \mathrm{mki} \cdot 4.2 .2021 .133-139$ 
masalah psikososial karena penerimaan dari masyarakat dan lingkungan [2].

Prevalensi kusta menurut World Health Organization [3] 6 dari 16 negara yang melaporkan lebih dari 1000 kasus kusta setiap tahunnya di wilayah Asia Tenggara. Pada tahun 2016 WHO juga telah mencatat secara global ada 216,108 kasus baru. Menurut Pusat Data dan Informasi Kementrian RI tahun 2018 Indonesia menempati urutan ke 6 dari 17 negara yang melaporkan angka kejadian baru penderita kusta yang melebihi 1000 penderita mulai tahun 2006 sampai tahun 2015. Dari data profil Dinas Kesehatan Kabupaten Jombang dari tahun 2011 sampai tahun 2017 di ketahui bahwa New Case Detected Rate (NCDR) kusta berhasil di turunkan pada tahun 2011 sampai 2016 sebanyak 8,53 penduduk menjadi 6.89 per 100.000 penduduk.

Pandangan masyarakat tentang kusta adalah sebagai penyakit turunan atau penyakit kutukan sehingga membuat anggota keluarga ataupun penderita kusta merasa terbebani dan stres dengan stigma tersebut. Stres pada keluarga merupakan sebuah masalah yang muncul yang disebabkan oleh ketidak efektifan sumber dan strategi koping yang adaptif sehingga kurang dapat mengatasi ancamanancaman stressor, sehingga keluarga tidak dapat memecahkan masalah dalam yang terjadi dalam keluarga dan berpengaruh pada kesejahteraan keluarga yang semakin menurun [4]. Stress yang dirasakan keluarga adalah menghadapi stigma masyarakat dan cara perawatan diri pada klien kusta.

Dampak ketidaktahuan keluarga dan pasien kusta cara perawatan akan menambah tingkat kecacatan penderita kusta dan masalah sosial yang di terima oleh keluarga dan penderita kusta adalah deskriminasi dan stigmatisasi [5] yang nantinya akan mendiskriminasi atau bahkan mengucilkan baik keluarga atau penderitanya. Selain itu adanya stigma juga dapat menyebabkan keluarga yang memiliki anggota yang terkena kusta mengalami perasaan malu, sedih, cemas, dan takut yang merupakan salah satu manifestasi dari harga diri rendah. Adanya harga diri rendah yang dialami oleh keluarga jika tidak segera diatasi dapat menyebabkan depresi bagi keluarga yang dapat menimbulkan terjadinya resiko bunuh diri [6]. Masalah fisik berdampak pada tingkat kemandirian penderita dan juga tergantung dari tingkat kecacatan khususnya dalam melakukan perawatan diri secara mandiri. Penatalaksanaan perawatan diri terhadap kusta dibagi menjadi non farmakologi dan farmakologi. Penatalaksanaan non farmakologi yang dapat dilakukan oleh keluarga adalah dengan melakukan perawatan pada bagian mata,tangan,kaki dan psikoedukasi [7].

Psikoedukasi merupakan salah satu metode yang memberikan informasi dan pendidikan kesehatan kepada keluarga melalui komunikasi dan hubungan yang terapeutik. Manfaat untuk penderita/penyintas kusta akan mendapatkan perawatan yang optimal dari keluarga dan mendapatkan dukungan dari keluarga. Adanya perlakuan perawatan yang optimal dan dukungan dari keluarga, secara tidak langsung dapat meningkatkan kemandirian keluarga penderita kusta dalam perawatan diri secara mandiri [8]. Salah satu tindakan yang dapat diupayakan untuk meningkatkan kemandirian keluarga dalam melakukan perawatan diri melalui terapi psikoedukasi keluarga adalah yang akan membahas tentang manajemen perawatan diri.

Penelitian ini bertujuan untuk mengetahui pengaruh terapi psikoedukasi terhadap perawatan diri keluarga.

\section{METODE}

Desain penelitian ini adalah praeksperimental one-group pra-post test design. Penelitian ini menggunakan pendekatan cross sectional. Populasi 
keluarga yang memiliki salah satu anggota keluarganya yang pernah terinfeksi kusta sebanyak 22 responden. Besar sampel sejumlah 22 responden dengan menggunakan teknik total sampling. Variabel independent psikoedukasi keluarga dan variabel dependent perawatan diri penyintas kusta. Tempat penelitian dilaksanakan di Puskesmas Mayangan Kabupaten Jombang.

Pada penelitian ini responden dilakukan psikoedukasi keluarga yang terdiri dari 2 sesi. Psikoedukasi keluarga dilaksanakan selama 3 minggu Minggu I tahap prestest dilanjutkan dengan identifikasi masalah dan health education mengenai kusta dan perawatannya, Minggu II tahapan manajemen kecemasan, manajemen beban dan pemberdayaan komunitas untuk membantu keluarga. Minggu III pembagian posttest serta follow up dari psikoedukasi keluarga yang telah dilakukan. Pengumpulan data pretest dengan melakukan observasi tentang kemampuan perawatan keluarga yang pada anggota keluarga yang pernah terinfeksi kusta. pada setiap sesi psikoedukasi keluarga dilakukan selama 45-60 menit pada tiap keluarga. Instrumen dalam penelitian menggunakan kuesioner dan lembar observasi. Kuisioner dikembangkan dengan mengacu pada teori Self Care yang telah dilakukan uji validitas $(0,781)$ dan reliabilitas $(0,752)$. Lembar observasi diisi oleh peneliti sebelum dilakukan psikoedukasi keluarga untuk mengetahui kemampuan keluarga dalam merawat anggota keluarga secara obyektif. Analisa data terdiri dari uji analisis univariat dan bivariat. uji analisis univariat untuk mengetahui distribusi frekuensi untuk data umum. uji analisis bivariat menggunakan uji Wilcoxon Signed Ranks Test untuk mengetahui pengaruh psikoedukasi keluarga terhadap kemampuan keluarga dalam perawatan diri penyintas kusta.

Penelitian ini juga memegang dan memperhatikan prinsip etik yang meliputi Nonmaleficien, Beneficence, Autonomy,
Anonymity, Confidentialy Justice, Veracity, Informed Concent Inducement. Penelitian ini telah mendapatkan ethical clearence dari komisi etik dengan no 0119040107/ KEPK/STIKES-PEMKAB/ JBG/IV/2019.

\section{HASIL}

Hasil penelitian menunjukkan bahwa sebelum dilakukan psikoedukasi keluarga, pada responden perempuan terdapat $(27,3 \%)$ melakukan perawatan diri kurang sebanyak 6 orang. Setelah dilakukan psikoedukasi keluarga pada responden perempuan terdapat $(40,9 \%)$ melakukan perawatan diri baik sebanyak 9 orang.

Hampir setengah $(31,8 \%)$ dari responden berusia 41-65 tahun melakukan perawatan diri kurang sebanyak 7 orang. Namun setelah dilakukan psikoedukasi keluarga, hampir setengah $(36,4 \%)$ dari responden usia 41-65 tahun melakukan perawatan diri baik sebanyak 8 orang.

Hasil penelitian menunjukkan bahwa setengah dari responden yang berpendidikan SMA yang melakukan perawatan diri kurang $(36,4 \%)$ sebanyak 8 orang, namun setelah dilakukan psikoedukasi keluarga pada responden yang berpendidikan SMA yang melakukan perawatan diri baik terdapat $(54,5 \%)$ sebanyak 12 orang.

Sebelum dilakukan psikoedukasi keluarga, pada responden hubungan dengan penyintas sebagai suami melakukan perawaam diri baik terdapat $(18,2 \%)$ sebanyak 4 orang. Namun setelah dilakukan psikoedukasi keluarga pada responden hubungan dengan penyintas sebagai suami melakukan perawatan diri baik terdapat $(22,7 \%)$ sebanyak 5 orang.

Berdasarkan tabel 2 menunjukkan bahwa sebagian besar $(54,5 \%)$ perawatan diri yang dilakukan keluarga adalah perawatan diri baik sebanyak 12 orang. Hampir seluruhnya $(77,3 \%)$ perawatan diri yang dilakukan keluarga setelah dilakukan 
psikoedukasi dalam katagori baik sebanyak 17 orang.

Berdasarkan hasil analisa data dengan menggunakan uji statistik Wilcoxon Signed Ranks Test dengan taraf signifikan $\alpha=0,05$ diperoleh hasil $\rho$-value $=0,025$ yang berarti $\rho$-value $<\alpha$ sehingga dalam penelitian ini $\mathrm{H} 1$ diterima yang artinya ada pengaruh psikoedukasi keluarga terhadap perawatan diri penyintas kusta.

Tabel1

Karakteristik Keluarga.

\begin{tabular}{lcc}
\hline \multicolumn{1}{c}{ Indikator } & $\mathrm{f}$ & $\%$ \\
\hline Jenis Kelamin & & \\
Perempuan & 12 & 54,5 \\
Laki-laki & 10 & 45,5 \\
\hline Umur & & \\
20-40 tahun & 10 & 45,5 \\
41-65 tahun & 12 & 54,5 \\
\hline Pendidikan & & \\
Dasar (SMP) & 6 & 27,2 \\
Menengah (SMA) & 16 & 7,2 \\
\hline Hubungan dengan penyintas & & 4 \\
Ayah & 1 & 18,1 \\
Ibu & 4 & 22,7 \\
Anak & 5 & 27,2 \\
Istri & 6 & 27,2 \\
Suami & 6 & \\
\hline
\end{tabular}

Tabel 2

Proporsi perawatan diri keluarga sebelum dan setelah dilakukan psikoedukasi keluarga

\begin{tabular}{lrrrrrr}
\hline \multirow{2}{*}{ Indikator } & \multicolumn{2}{c}{ Sebelum intervensi } & \multicolumn{2}{c}{ Setelah intervensi } & \multirow{2}{*}{$\mathrm{p}$} \\
\cline { 2 - 4 } & $\mathrm{f}$ & $\%$ & $\mathrm{f}$ & $\%$ & \\
\hline Perawatan Diri & 12 & 54,5 & 17 & 77,3 & \multirow{2}{*}{$0,025^{*}$} \\
Baik & 10 & 45,5 & 5 & 22,7 & \\
$\quad$ Kurang & & & & \\
\hline
\end{tabular}

* Wilcoxon test

\section{PEMBAHASAN}

Perawatan diri dapat dipergunakan untuk tidak menambah kecacatan baru dan kerusakan fisik penyintas serta dapat menurunkan derajat keparahan kecacatan yang sudah ada agar penyintas kusta tetap dapat melakukan produktivitas. Perawatan diri merupakan hal yang harus diperhatikan agar kecacatan yang dialami tidak semakin parah [9]. Untuk mengatasi keterbatasan tersebut, salah satu tindakan yang tepat dengan psikoedukasi keluarga. Psikoedukasi keluarga memberikan dampak positif kepada keluarga yaitu dapat meningkatkan dan menambah kemampuan keluarga dalam melakukan perawatan diri secara mandiri di rumah [8].

Terapi ini terdiri dari 2 sesi yang mana dalam penelitian ini setiap sesi dilaksanakan selama 45-60 menit. Sesi pertama psikoedukasi keluarga membahas tentang identifikasi masalah keluarga dan cara merawat pasien dengan kusta pada penelitian ini dibahas tentang masalah dalam merawat kusta, didapatkan hasil bahwa hampir semua keluarga merasakan cemas ketika merawat kusta, masalah dalam merawat, kebanyakan keluarga mengatakan bahwa masalah dalam merawat anggota keluarga yang pernah terinfeksi kusta antara lain pemahaman yang kurang, kurangnya motivasi antar 
anggota keluarga sehingga membuat keluarga tidak tahu cara merawat, adapun keinginan/harapan keluarga mengikuti terapi ini adalah agar keluarga dapat meningkatkan kemampuan dalam merawat, kemudian tentang manajemen perawatan kusta, sesi kedua membahas tentang manajemen kecemasan, manajeman beban keluarga dan pemberdayaan komunitas untuk membantu keluarga [8].

Hasil penelitian menunjukkan terdapat pengaruh psikoedukasi keluarga terhadap perawatan diri penyintas kusta yang dibuktikan dengan adanya perubahan tingkat kemampuan keluarga yang sebelumnya mayoritas melakukan perawatan diri dalam katagori kurang menjadi baik setelah dilakukan psikoedukasi keluarga. Hal ini dikarenakan keluarga telah memahami cara merawat penyintas. Psikoedukasi keluarga ini merupakan terapi yang lengkap karena memberikan pendidikan kesehatan dengan metode pendekatan secara psikis. Keluarga dengan anggota penyintas kusta memerlukan edukasi yang lengkap, termasuk pendampingan tenaga kesehatan profesional untuk meningkatkan kualitas hidup penyintas kusta dan keluarganya [10]. Psikoedukasi ini juga dapat membekali keluarga bagaimana mengelola kecemasan dan beban selama merawat maupun saat rehabilitasi anggota keluarga sampai dapat kembali lagi ke masyarakat.

Sesi pertama psikoedukasi keluarga, akan mendapatkan informasi tentang kusta, informasi cara merawat kusta dan melakukan diskusi bersama dengan peneliti dan anggota keluarga yang lain terkait perawatan kusta. Sebelum dilakukan psikoedukasi keluarga, keluarga jarang melakukan perawatan diri terhadap anggota keluarga yang pernah terinfeksi kusta. Namun setelah psikoedukasi keluarga, keluarga memulai untuk melakukan perawatan diri dengan cara memberikan pengarahan, pmbelajaran, pelatihan secara bertahap dan berkelanjutan. Adanya psikoedukasi keluarga mampu merubah perilaku keluarga dalam melakukan perawatan diri [11].

Selain dapat meningkatkan kemampuan dan kemandirian keluarga dalam melakukan perawatan, terapi ini juga membantu keluarga dalam mengatasi kecemasan dan beban yang dirasakan selama merawat kusta. Adanya kecemasan yang dirasakan keluarga berhubungan dengan pandangan negatif atau stigma masyarakat tentang kusta. Hal ini sesuai dengan penelitian yang dilakukan oleh (Somar, Waltz and van Brakel (2020) yang menyatakan bahwa dampak dari ketidaktahuan cara perawatan akan menambah tingkat kecacatan penderita kusta dan masalah sosial yang di terima oleh keluarga dan penderita kusta adalah deskriminasi dan stigmatisasi. Melalui psikoedukasi keluarga, akan diajarkan cara mengurangi kecemasan yaitu dengan teknik relaksasi atau deep breathing. Melakukan relaksasi nafas dalam dapat meningkatkan konsentrasi dan mempermudah dalam pengaturan nafas, meningkatkan kadar oksigen di dalam darah, menurunkan hormon adrenalin dan memberikan rasa yang tenang. Teknik nafas dalam juga mampu membantu relaksasi otot pembuluh darah sehingga membuat aliran darah ke seluruh tubuh menjadi lancar [13]. Penatalaksanaan relaksasi nafas dalam dapat memberikan ketenangan jiwa sehingga berdampak pada penurunan tekanan darah dan relaksasi nafas dalam dapat dilakukan mandiri, mudah diaplikasikan dan tidak memerlukan waktu yang lama untuk dilakukan [14]. Psikoedukasi keluarga juga mampu mengatasi kecemasan yang dirasakan keluarga dalam merawat anggota keluarganya yang sakit [15].

Adapun beban yang dirasakan keluarga dalam merawat kusta antara lain perasaan sedih, khawatir dan cemas yang merupakan beban subjektif. Sedangkan beban objektif yang dialami keluarga 
antara lain kelelahan dalam merawat, hambatan dalam bersosialisasi dalam keluarga dan pandangan buruk masyarakat ,dalam hal ini keluarga mengatakan masih banyak orang dilingkungan sekitar yang memiliki pandangan buruk pada kusta dan sering kali dikaitkan dengan penyakit kutukan. Keluarga merasa memiliki waktu yang sedikit, merasa lelah, merasa khawatir tentang masa depan keluarganya, dan adanya respon negatif dari lingkungan sekitar atau orang lain tentang kondisi keluarganya membuat sedih (Anggreni \& Valentina, 2015).

Terapi ini membantu keluarga untuk mengatasi hambatan dalam merawat kusta. Dalam penelitian ini, hambatan dalam merawat kusta antara lain waktu dalam melakukan perawatan kusta yang biasanya sering kali dirasakan oleh keluarga yang bekerja dan terkadang keluarga merasa malu dalam merawat anggota yang menderita kusta Melalui terapi ini, keluarga diajarkan cara berbagi peran dalam keluarga. Keluarga memegang peran yang sangat penting dalam memberikan support untuk anggota keluarga yang sakit [17]. Setelah dilakukan psikoedukasi keluarga, peran dalam keluraga dapat dibagi dan dapat meningkatkan kesejahteraan semua anggota keluarga. Seluruh anggota keluarga dapat berperan aktif dalam melakukan perawatan diri pada keluarga dan mampu memberikan perawatan pada anggota keluarga yang merupakan penyintas kusta.

\section{SIMPULAN}

Sebagian besar tingkat kemampuan keluarga dalam melakukan perawatan diri penyintas kusta sebelum dan sesudah dilakukan psikoedukasi keluarga mengalami peningkatan. Psikoedukasi keluarga terbukti efektif dalam meningkatkan kognitif dan psikomotor keluarga dalam perawatan diri penyintas kusta.
Diharapkan agar keluarga tetap melakukan hal-hal yang sudah diajarkan dalam psikoedukasi keluarga secara mandiri sehingga perawatan diri kepada anggota keluarga yang pernah terinfeksi kusta dapat berjalan dengan baik, rutin dan teratur.

\section{UCAPAN TERIMAKASIH}

Penulis menyampaikan terimakasih kepada semua pihak yang telah membantu dalam proses penelitian ini. Penulis khususnya ingin menyampaikan terimakasih dan apresiasi yang setinggi-tingginya kepada Ketua STIKES Pemkab Jombang atas dukungan dan kesempatan yang telah diberikan untuk penulis sehingga dapat menyelesaikan penelitian ini. Penulis juga menyampaikan terimakasih kepada Kepala Puskesmas Mayangan yang turut membantu dalam penelitian ini serta seluruh responden yang terlibat dalam penelitian ini.

\section{REFERENSI}

[1] Kementrian Kesehatan R. Infodatin kusta 2018. Jakarta: Kementrian Kesehatan RI; 2018.

[2] Pribadi T. Stigmatisasi penderita kusta di desa sidodadi asri banjar agung lampung selatan. J Kesehat Holistik 2016;10:1-4.

[3] WHO. Leprosy 2013:18.

[4] Maryam S. Stres keluarga: Model dan pengukurannya. J Psikoislamediaournal Psikoislamedia 2016;1st:335-43.

[5] Tarigan NP. Masalah kusta dan diskriminasi serta stigmatisasinya di indonesia. Humaniora 2013;4:432-44.

[6] Wulandari RA, Soeharto, Setyawati S. Pengaruh terapi psikoedukasi keluarga terhadap harga diri rendah dan beban keluarga dengan anak retardasi mental. J Ilmu Keperawatan 2016;4th:184-204.

[7] Varcarolis, E.M., Carson VB and S. Competency based curruculum education in mental health nursing,. Open J Nurs 2013;3.

[8] FIK UI. Modul psychoeducation therapy (terapi psikoedukasi keluarga) pada klien schizophrenia. Jakarta: Universitas Indonesia; 2012.

[9] Astutik E, Kiptiyah NM. Faktor-faktor yang 
berhubungan dengan perilaku perawatan diri eks-penderita kusta di unit pelaksana teknis rehabilitasi sosial eks-penderita kusta nganget, tuban, jawa timur. J Epidemiol Kesehat Indones 2016;1:15-21.

[10] Freitas BHBM de, Silva FBE, Jesus JMF de, Alencastro MAB. Leprosy educational practices with adolescents: an integrative literature review. Rev Bras Enferm 2019;72:1397-404. https://doi.org/10.1590/0034-7167-20170458.

[11] Bangun AV, Safarina L, Ningsih F. Pengaruh terapi psikoedukasi terhadap self care activity pada penderita diabetes militus di rw 07 wilayah kerja puskesmas Cimahi Tengah. Pinlitmas 1 2018;1:250-7.

[12] Somar P, Waltz M, van Brakel W. The impact of leprosy on the mental wellbeing of leprosyaffected persons and their family members - a systematic review. Glob Ment Heal 2020;7. https://doi.org/10.1017/gmh.2020.3.

[13] Ramasamy S, Panneerselvam S, Govindharaj P, Kumar A, Nayak R. Progressive muscle relaxation technique on anxiety and depression among persons affected by leprosy. J Exerc Rehabil 2018;14:375-81. https://doi.org/10.12965/jer.1836158.079.

[14] Inra, Hariyanto T, Adi R catur. Perbedaan tingkat kecemasan lansia sebelum dan sesudah diberikan terapi relaksasi nafas dalam di kelurahan tlogomas Malang. Nurs News (Meriden) 2019;4.

[15] Rosmaharani S. Pengaruh psikoedukasi keluarga terhadap perubahan tingkat kecemasan dan persepsi beban keluarga merawat anak dengan retardasi mental di slb negeri kabupaten Jombang. Indoenesian J Heal Sci 2015;5:213-21.

[16] Anggreni NM, Valentina TD. Penyesuaian psikologis orangtua denga anak down syndrome. J Psikol Udayana 2015;2:185-97.

[17] Ebenso B, Newell J, Emmel N, Adeyemi G, Ola B. Changing stigmatisation of leprosy: An exploratory, qualitative life course study in Western Nigeria. BMJ Glob Heal 2019;4:1-12. https://doi.org/10.1136/bmjgh-2018-001250. 